\title{
Análisis de simulaciones computacionales para la enseñanza del modelo de evolución biológica por selección natural
}

\author{
Gisella Mabel Della costa \\ Centro de Investigaciones Geológicas Aplicadas. CONICET. Córdoba. Argentina. \\ gisebiodellacosta@gmail.com \\ ORCID: bttps:/ / orcid.org/0000-0002-2492-1985
}

\author{
Maricel Occelli \\ EDUCEV A-CienciaTIC. Departamento de Enseñanza de la Ciencia y la Tecnología. Facultad de \\ Ciencias Exactas, Físicas y Naturales. Universidad Nacional de Córdoba. CONICET. Córdoba. \\ Argentina.maricel.occelli@unc.edu.ar \\ ORCID: http:/ / orcid.org/0000-0002-4516-0644
}

[Recibido: 21 Diciembre 2018. Revisado: 15 Abril 2019. Aceptado: 25 Enero 2020]

Resumen: La teoría de la evolución resulta clave para abordar la enseñanza de los procesos biológicos y es el eje fundamental de toda la biología. Sin embargo, se registran dificultades para la comprensión de la evolución por selección natural tanto en estudiantes de escuela secundaria como de nivel universitario. Las simulaciones computacionales utilizadas como recursos didácticos pueden obstaculizar o favorecer la comprensión de la evolución en función de sus particularidades. En el presente trabajo se analizan los aspectos técnicos, conceptuales y didácticos de diez simulaciones computacionales del proceso de evolución biológica, con la finalidad de evaluar el potencial de estos recursos para la enseñanza del modelo de evolución biológica por selección natural. A partir de los resultados obtenidos encontramos simulaciones que podrían fortalecer las concepciones alternativas que tienen los estudiantes acerca de cómo funciona la evolución y otras que podrían mejorar la comprensión de los principios que estructuran la teoría de la evolución por selección natural.

Palabras clave: Simulaciones computacionales; Recursos didácticos; Enseñanza de la Biología; Evolución; Selección Natural

\section{Analysis of Computer Simulations for the Teaching of the Model of Evolution by Natural Selection}

\begin{abstract}
The theory of evolution is nowadays considered as the backbone of all biology, and is essential to approach the teaching of biological processes. However, there are difficulties in understanding evolution by natural selection in both secondary and university students. Employing computer simulations in teaching evolution are didactic resources that could hinder or promote understanding depending on their specific aspects. The technical, conceptual and didactic aspects of ten computer simulations of the process of biological evolution are analyzed in this work, in order to evaluate the potential that these resources have for the teaching of the model of biological evolution by natural selection. From the results, we find that there are simulations that could strengthen the alternative conceptions that the students have about how evolution works, whereas others could improve the understanding of the principles that structure the theory of evolution by natural selection.
\end{abstract}

Keywords: Computer Simulations; Didactic Resources; Biology Teaching; Evolution; Natural Selection

Para citar este artículo: Della costa, G.M. y Occelli, M. (2020) Análisis de simulaciones computacionales para la enseñanza del modelo de evolución biológica por selección natural. Revista Eureka sobre Enseñanza y Divulgación de las Ciencias 17(2), 2201. doi: 10.25267/Rev_Eureka_ensen_divulg_cienc.2020.v17.i2.2201

\section{Introducción}

Diferentes investigaciones han registrado dificultades en la comprensión del modelo de evolución por selección natural (MESN) tanto para estudiantes de escuela secundaria como en el nivel universitario (Bermúdez 2015, Rivas y González-García 2016, González-Galli y Meinardi 2017, Ruiz-Gutiérrez, Álvarez-Pérez, Noguera-Solano y Esparza-Soria 2012). Estos

\author{
Revista Eureka sobre Enseñanza y Divulgación de las Ciencias \\ Universidad de Cádiæ. APAC-Eureka. ISSN: 1697-011X \\ http:/ / dx.doi.org/10.25267/Rev_Eureka_ensen_divulg_cienc.2020.v17.i2.2201 \\ http:/ / reuredc.uca.es
}


obstáculos se relacionan con la naturaleza de los procesos evolutivos la cual implica pensar en cambios a nivel poblacional que tienen lugar en largos períodos de tiempo y en la reproducción diferencial de los individuos (González-Galli y Meinairdi 2015). La incorporación de simulaciones como herramientas metodológicas podría favorecer la comprensión del MESN ya que permiten explorar fenómenos inobservables; relacionar fenómenos observables y no observables; realizar múltiples experimentos en un corto período de tiempo y poner a prueba hipótesis que no podrían ser probadas de otra manera debido a limitaciones físicas o temporales (de Jong, Linn y Zacharia 2013).

En particular, las investigaciones en el campo de la didáctica de las ciencias demuestran que la utilización de simulaciones computacionales favorece la comprensión de los procesos evolutivos en un contexto de aprendizaje apropiado (Herrero, del Castillo, Monjelat, GarcíaVarela, Checa y Gómez 2014, Garófalo, Chemes y Alonso 2016, Roldán-Segura, PeralesPalacios, Ruiz-Granado 2018). Sin embargo, en el campo de la didáctica de las ciencias, también se registran estudios que enfatizan la necesidad de evaluar las simulaciones ya que la forma en que se represente un fenómeno u objeto de estudio podría funcionar como obstáculo epistemológico (Pessanha, Couso y Pietrocola 2013). Por lo tanto, considerando que estos recursos podrían favorecer u obstaculizar la comprensión de la evolución, el objetivo de este trabajo es aportar una caracterización de simulaciones para la enseñanza del MESN en función de sus aspectos técnicos, conceptuales y didácticos.

\section{Referentes teóricos}

En esta sección presentamos los fundamentos en los cuales basamos esta investigación. Primero nos referimos a la teoría de la evolución biológica como eje estructurante de la biología y a los distintos modelos que forman parte de esta teoría, luego definimos qué entendemos como modelo conceptual y cuáles son los obstáculos que dificultan la comprensión del MESN. Por último, sintetizamos las principales cuestiones que han sido destacadas por las investigaciones referidas al uso de simulaciones computacionales en la enseñanza de la biología y específicamente de la evolución biológica.

\section{La teoría de la evolución biológica}

La teoría de la evolución permite abordar la complejidad de los procesos biológicos y es el eje fundamental de toda la biología. En el ámbito académico, todos los años se produce una gran cantidad de artículos y libros relacionados con esta teoría, manifestándose su carácter vigente, actual y dinámico (Azcárraga 2009). Además, la evolución biológica permite explicar múltiples temáticas como la diversidad actual de los seres vivos, la mayor frecuencia de enfermedades genéticas en ciertos grupos étnicos, la problemática de la resistencia de las bacterias a los antibióticos, el origen de las especies domésticas y de interés comercial, entre muchas otras. También permite conocer los debates ideológicos que surgieron durante la formulación de las distintas teorías evolutivas y sus reformulaciones (Román y Capozzo 2010).

La teoría de la evolución biológica se compone de un conjunto de modelos explicativos relacionados con otros fenómenos biológicos como la adaptación, especiación, reproducción, etc. (González-Galli, Adúriz-Bravo y Meinardi 2005). Los principios esenciales de los que depende la evolución son variabilidad, heredabilidad y aptitud (Lewontin 1970, Horwitz 2013). A lo largo de la historia han existido debates en torno a la especiación y el rol de la especie en la evolución surgiendo distintos modelos para explicar este fenómeno, entre los que se encuentra el modelo de especiación simpátrica. Según este modelo, las nuevas especies aparecen por divergencia gradual a partir de una población homogénea y el modelo de especiación alopátrica que considera el origen de las especies como un proceso al azar en el 
que la aparición de barreras geográficas separan a dos poblaciones de una misma especie que con el tiempo se transforman en dos especies distintas. Otro objeto de debate fue el ritmo de la evolución. El modelo de equilibrios punteados, contraponiéndose al gradualismo filético propuesto por Darwin, propone que la evolución se caracteriza por largos periodos de estabilidad morfológica cortados bruscamente por cambios puntuales que darían lugar a nuevas especies. Así la discontinuidad del registro fósil y la estabilidad de las especies son fenómenos congruentes con el modelo de especiación peripátrica según el cual las nuevas especies surgen a partir de pequeñas poblaciones aisladas en la periferia de las áreas de distribución de la especie antecesora (Gould 2002, Agusti 2010). La Teoría Sintética de la evolución es la teoría más aceptada por la comunidad científica actualmente e integra la evolución por selección natural de Darwin, la genética como base de la herencia, la mutación aleatoria como fuente de la variabilidad y los principios de la genética de poblaciones. Cabe destacar que en los últimos tiempos, se han propuesto otros mecanismos como la deriva génica, la migración y la mutación como posibles alternativas al mecanismo de selección natural (Folguera y González-Galli 2012).

\section{El uso de simulaciones para la enseñanza de las ciencias}

La investigación en didáctica de las ciencias ha identificado que las concepciones alternativas que tienen los estudiantes funcionan como obstáculos epistemológicos para el aprendizaje del MESN (Bermúdez 2015, González-Galli y Meinardi 2015, Rivas y González-García 2016). Algunas concepciones aluden a razonamientos teleológicos que proporcionan explicaciones finalistas para los cambios evolutivos y razonamientos esencialistas que consideran a las especies como categorías estables en las que la variabilidad de caracteres no modifica la esencia de las mismas (Pérez, Gómez Galindo y González-Galli 2018). El razonamiento teleológico tiene su origen en el proceso de constitución histórica de la biología como disciplina y es considerado una problemática central en la enseñanza de la evolución biológica por selección natural (González-Galli y Meinardi 2017). Entonces identificamos que el problema fundamental se encuentra relacionado con la manera de presentar los conceptos asociados al MESN para superar las dificultades mencionadas.

En relación al uso didáctico de las simulaciones en la enseñanza de las ciencias, se registran numerosas investigaciones (Pontes 2005, Rivero y Mendoza 2005, Torres-Zúñíga 2011, Fernández-Cesar y Aguirre-Pérez 2012, Ardura y Zamora 2014, Occelli y Malin Vilar 2018, Occelli y Garcia-Romano 2018). Estos trabajos destacan las ventajas de la utilización de estos recursos pero también la necesidad de elaborar un diseño didáctico adecuado para su integración como estrategia de enseñanza. Alzugaray, Carreri y Marino (2009), sostienen que los docentes deben acompañar la inclusión de tecnologías en las aulas, con un proceso reflexivo que fundamente su elección, considerando que el planteamiento metodológico y el diseño respondan a los objetivos de enseñanza propuestos. Las principales ventajas que presentan las simulaciones es que permiten la construcción de modelos mentales para superar las dificultades que se establecen entre el modelo conceptual que enseña el docente y las representaciones que tienen los alumnos de los fenómenos observados (Ortiz Benavides y Piña López 2018).

Entendemos como modelo conceptual a una construcción representacional mediadora entre el campo teórico y el campo empírico (Giere 2005, Adúriz-Bravo y Ariza 2014, Lombardi 2010). Los modelos pueden expresarse en una variedad de formas o representaciones a partir de diversos registros semióticos y utilizando múltiples soportes (Evagorou, Erduran y Mäntylä 2015). En este sentido, las simulaciones constituyen una representación dinámica e interactiva de modelos conceptuales. Esto significa que la base o el núcleo de una simulación es una 
teoría y en definitiva también se podría decir que en esencia, las simulaciones computacionales son modelos teóricos (Smetana y Bell 2012). En la programación de una simulación computacional los modelos teóricos se traducen en algoritmos y códigos que responden a un sistema de ideas y condiciones (Develaki 2017). Estos programas permiten visualizar el desarrollo de procesos simples o complejos, la evolución de un sistema, la interacción entre los elementos que lo integran o las consecuencias de tales interacciones (Occelli y Garcia Romano 2018). En particular, los modelos analógicos son representaciones del objeto de estudio, que permiten una mejor visualización y percepción de los fenómenos involucrados para así actuar como facilitadores del aprendizaje. Sin embargo, la forma de representar el objeto y/o fenómeno, al mismo tiempo puede funcionar como obstáculos del aprendizaje (Pessanha, Couso y Pietrocola 2013).

Específicamente para la enseñanza del MESN, las investigaciones referidas a la utilización de simulaciones evidencian que facilitan la introducción de conceptos esenciales para la comprensión de este modelo. Así, en el estudio llevado a cabo por Herrero et al. (2014), la utilización del videojuego Spore, contribuyó a crear un contexto de aprendizaje donde los estudiantes exploraron sus ideas previas acerca del proceso de evolución por selección natural. Otra propuesta interesante fue la utilización del software Forensic EA Lite, el cual facilitó el aprendizaje de las bases moleculares de la evolución y permitió a los estudiantes analizar sus propios modelos de pensamiento y dificultades. Además evidenció la necesidad de reforzar ciertos contenidos teóricos de las bases del proceso de evolución por selección natural (Garófalo et al. 2016). Por último, el uso del videojuego Plague Inc: Evolved fue adecuado para generar situaciones de enseñanza compartida mediante un intercambio de roles entre docente y estudiantes (Scally, Alonso y Garófalo 2015).

En síntesis la utilización de simulaciones como herramienta de enseñanza presenta múltiples ventajas, sin embargo su integración en diseños didácticos concretos requiere que los profesores conozcan las características, las potencialidades y las limitaciones de estos recursos (Contreras Gelves y Carreño-Moreno 2012, Cataldi, Lage y Dominighini 2013, ValverdeCrespo, De Pro y González-Sánchez 2018). Es por ello que en este trabajo, se pretende aportar información sobre un grupo de simulaciones referidas al proceso de evolución biológica por selección natural.

\section{Metodología}

Se realizó un estudio documental descriptivo, interpretativo y analítico utilizando la técnica de análisis de contenido (Bardin 1986) para analizar el potencial de las simulaciones computacionales para la enseñanza del MESN. La muestra fue definida a partir de una búsqueda exhaustiva de simulaciones disponibles en la Web durante los meses de Septiembre y Octubre del año 2018, utilizando los siguientes términos: "simulaciones de la evolución biológica"; "software educativos"; "juegos de evolución biológica"; "simulaciones para la enseñanza de la evolución por selección natural". Así, se encontró un total de 35 simulaciones de las cuales se seleccionaron 10 para este estudio. Se excluyeron las simulaciones que necesitaban una versión anterior a Windows 2007 y aquellas que se encontraban en un mismo sitio web seleccionando solo 1 de esos sitios para este estudio a modo representativo.

En un primer momento, a partir de los aportes teóricos reseñados en este artículo se construyeron dos dimensiones de análisis: Aspectos técnicos y Aspectos didácticos. Para cada dimensión se establecieron categorías y sus correspondientes indicadores. Luego las simulaciones fueron utilizadas por una de las integrantes del grupo de investigación para conocer el funcionamiento de las mismas. En función de las características y regularidades 
identificadas, se re definieron junto a la otra integrante del grupo de investigación las categorías e indicadores de las dimensiones Aspectos técnicos y Aspectos didácticos y se construyó una dimensión denominada Aspectos conceptuales para referirnos específicamente al MESN ya que esta primera utilización de las simulaciones permitió identificar que la representación del proceso de evolución es diferente en cada uno de estos recursos. Finalmente las simulaciones fueron utilizadas reiteradas veces por una de las integrantes con la finalidad de registrar los indicadores de las categorías referidas a las dimensiones definidas en este estudio. A continuación se describen cada una de las dimensiones definidas para analizar las simulaciones seleccionadas.

\section{Aspectos técnicos}

Dentro de esta dimensión se incluyen aspectos relacionados con la instalación y/o uso de la simulación, los componentes de la interfaz gráfica y las funciones extras. En cuanto a la instalación se identifican cuestiones como la conexión a Internet, los softwares con los cuales se puede ejecutar la simulación y el idioma en el cual se encuentra. Considerando que la interfaz gráfica debe proporcionar un entorno visual atractivo para que el usuario capte y asimile la información presentada por la simulación (Garcia-Romano y Occelli 2019), se definieron dos niveles de calidad (alta-baja) de los componentes visuales en función del tipo de imágenes, la resolución y contraste de las imágenes, el nivel de detalle de las imágenes e iconografía y la manera en la que se representa el espacio en las simulaciones. También se incluye la disponibilidad de materiales o funciones extras que pudieran facilitar la utilización del recurso. En la Tabla 1 se detallan las categorías e indicadores correspondientes para esta dimensión.

Tabla 1. Categorías e indicadores de la dimensión aspectos técnicos

\begin{tabular}{|c|c|}
\hline Categorías & Indicadores \\
\hline \multirow[b]{2}{*}{ Conexión a Internet } & Si: la conexión a Internet es indispensable para el uso la simulación. \\
\hline & $\begin{array}{l}\text { No: la conexión a Internet no es necesaria para el uso de la simulación ya que } \\
\text { se puede descargar en un ordenador. }\end{array}$ \\
\hline \multirow{9}{*}{$\begin{array}{l}\text { Sofware en los que se puede } \\
\text { ejecutar }\end{array}$} & Microsoff Windows XP/vista 7/8.1/10 \\
\hline & Linux \\
\hline & Masintosh \\
\hline & Mavericks \\
\hline & Android \\
\hline & Java/Java Laucher App \\
\hline & $\mathrm{iPad}$ \\
\hline & Phone \\
\hline & Ios \\
\hline \multirow{6}{*}{ Idioma } & Español \\
\hline & Catalán \\
\hline & Inglés \\
\hline & Francés \\
\hline & Portugués \\
\hline & Otros \\
\hline
\end{tabular}


Tabla 1. Continuación

\begin{tabular}{|c|l|}
\hline \multicolumn{1}{|c|}{ Categorías } & \multicolumn{1}{|c|}{ Indicadores } \\
\hline \multirow{5}{*}{$\begin{array}{c}\text { Calidad de los componentes } \\
\text { visuales }\end{array}$} & $\begin{array}{l}\text { Baja: las imágenes utilizadas en la simulación son 2D generalmente } \\
\text { interactivas, no tienen alta resolución y contraste y el nivel de detalle de las } \\
\text { imágenes e iconografía es bajo. El espacio se representa de manera } \\
\text { bidimensional. }\end{array}$ \\
\cline { 2 - 3 } Material y/o funciones extras & $\begin{array}{l}\text { Alta: las imágenes utilizadas en la simulación son 3D tienen alta resolución y } \\
\text { contraste, el nivel de detalle de las imágenes e iconografía es alto. El espacio se } \\
\text { representa de manera bidimensional o tridimensional. }\end{array}$ \\
\hline \multirow{5}{*}{} & Tutorial \\
\cline { 2 - 3 } & Guía para el docente \\
\cline { 2 - 3 } & Diccionario \\
\cline { 2 - 2 } & Menú informativo \\
\cline { 2 - 2 } & Posibilidad de guardar las actividades realizadas \\
\hline
\end{tabular}

\section{Aspectos conceptuales}

Esta dimensión de análisis intenta caracterizar los modelos que subyacen en las simulaciones, las variables y/ o factores del MESN incluidos en la simulación, el nivel de organización en el que ocurre la evolución y el tipo de organismo representado en la simulación. Se definieron tipos de modelo a partir del comportamiento de las variables en función del tiempo (modelo discreto o continuo) y la incorporación de algún componente aleatorio en el sistema (modelo determinista o estocástico). En la Tabla 2 se detallan las categorías e indicadores correspondientes para esta dimensión.

Tabla 2. Categorías e indicadores de la dimensión aspectos conceptuales

\begin{tabular}{|c|c|}
\hline Categorías & Indicadores \\
\hline \multirow{4}{*}{ Tipo de modelo } & $\begin{array}{l}\text { Discreto: las variables incluidas en el modelo cambian de estado en un instante de tiempo } \\
\text { determinado. }\end{array}$ \\
\hline & $\begin{array}{l}\text { Continuo: las variables incluidas en el modelo cambian de estado continuamente en el } \\
\text { tiempo. }\end{array}$ \\
\hline & $\begin{array}{l}\text { Determinista: el resultado del sistema depende solo de los factores de entrada definidos por } \\
\text { el usuario. }\end{array}$ \\
\hline & $\begin{array}{l}\text { Estocástico: el resultado del sistema depende de los factores de entrada definidos por el } \\
\text { usuario y de algún factor aleatorio. }\end{array}$ \\
\hline \multirow{11}{*}{$\begin{array}{l}\text { Variables y/o } \\
\text { factores del } \\
\text { MESN incluidos } \\
\text { en la simulación }\end{array}$} & Tasa de mutación \\
\hline & Tasa de migración \\
\hline & Tasa de reproducción \\
\hline & Tasa de supervivencia \\
\hline & Variabilidad fenotípica \\
\hline & Variabilidad genética \\
\hline & Constitución genética \\
\hline & Número de individuos \\
\hline & Número de generaciones \\
\hline & Cambio fenotípico \\
\hline & Presiones selectivas \\
\hline
\end{tabular}


Tabla 2. Continuación

\begin{tabular}{|c|l|}
\hline Categorías & \multicolumn{1}{c|}{ Indicadores } \\
\hline $\begin{array}{c}\text { Nivel de } \\
\text { organización en el } \\
\text { que ocurre la } \\
\text { evolución }\end{array}$ & Molecular: la selección ocurre a nivel de genes. \\
\cline { 2 - 2 } & Individuos: los cambios fenotípicos y/o selección ocurren en un solo organismo. \\
\cline { 2 - 2 } \begin{tabular}{c} 
Tipo de organismo $\begin{array}{c}\text { Población: los cambios fenotípicos y/o selección ocurren en un conjunto de organismos. } \\
\text { utilizado en la } \\
\text { simulación }\end{array}$ \\
\cline { 2 - 2 }
\end{tabular} & $\begin{array}{l}\text { Símbolo no específico: los organismos se representan con figuras geométricas o formas no } \\
\text { reconocibles. }\end{array}$ \\
\cline { 2 - 3 } & $\begin{array}{l}\text { Entidad biológica reconocida: los organismos representados son reconocibles (plantas, } \\
\text { Avatar: los organismos se representan con una identidad virtual que elige el usuario para } \\
\text { que lo represente en la simulación. }\end{array}$ \\
\hline
\end{tabular}

\section{Aspectos didácticos}

En esta dimensión de análisis se hizo hincapié en el manejo de la simulación y en las posibilidades cognitivas que ofrecen las simulaciones según su nivel de interactividad entendido como las oportunidades dialógicas entre usuario y simulación propuestas (Estebanell Minguell, 2002). Un recurso educativo es interactivo si el código que utiliza el material es comprendido por el usuario y le permite: encontrar los contenidos y actividades que precisa según sus propias necesidades; identificar diferentes formas en la presentación de los contenidos siguiendo criterios de significación para interpretar la sintaxis de la comunicación y conectar palabras e imágenes de la simulación con la información que posee; realizar un manejo intuitivo por analogía entre las imágenes o íconos ofrecidos y el tipo de información al que refieren; seguir rutas múltiples para avanzar y progresar; recibir información de retorno de cada una de las actividades propuestas y encontrar información que fomente su metacognición (Estebanell Minguell, 2002; Zangara y Sanz 2012). En función de ello se definieron cuatro categorías para identificar el nivel de interactividad proporcionado al usuario: Nivel de manipulación de variables; Recorridos propuestos, Orientación al usuario y Retroalimentación proporcionada al usuario. En la Tabla 3 se detallan las categorías e indicadores correspondientes para esta dimensión.

Tabla 3. Categorías e indicadores de la dimensión aspectos didácticos

\begin{tabular}{|c|c|}
\hline Categorías & Indicadores \\
\hline \multirow{3}{*}{$\begin{array}{l}\text { Nivel de manipulación } \\
\text { de variables }\end{array}$} & Bajo: se puede modificar una sola variable. \\
\hline & Medio: se pueden modificar de 2 a 4 variables. \\
\hline & Alto: se pueden modificar 4 o más variables. \\
\hline \multirow{3}{*}{ Recorridos propuestos } & Cerrado: incluye un único itinerario a seguir. \\
\hline & Semiabierto: incluye entre 2 y 4 itinerarios a seguir. \\
\hline & Abierto: incluye más de 4 itinerarios a seguir. \\
\hline \multirow{3}{*}{ Orientación al usuario } & Guiado: proporciona directivas al usuario. \\
\hline & Semiguiado: proporciona directivas a demanda del usuario. \\
\hline & Intuitivo: no proporciona directivas al usuario. \\
\hline \multirow{2}{*}{$\begin{array}{c}\text { Retroalimentación } \\
\text { proporcionada al } \\
\text { usuario }\end{array}$} & $\begin{array}{l}\text { Baja: el usuario no puede observar de manera gráfica y/o numérica cómo se modifica } \\
\text { el modelo, cuando cambia el valor de las variables. }\end{array}$ \\
\hline & $\begin{array}{l}\text { Alta: el usuario puede observar cómo se modifica de manera gráfica y/o numérica el } \\
\text { modelo cuando cambia el valor de las variables. }\end{array}$ \\
\hline
\end{tabular}


A continuación se especifican siguiendo un orden alfabético las 10 simulaciones analizadas y se realiza una descripción de cada una indicando los desarrolladores o autores, el tipo de acceso, el sitio donde se encuentra disponible, el contexto temático, el escenario simulado, el recorrido que debe seguir el usuario y el objetivo de la actividad o misión propuesta.

\section{Avida}

Es un desarrollo de la Universidad de Michigan que puede descargarse de manera libre y sin costo desde https://avidaed.msu.edu/app/Avi daED.html Las poblaciones se encuentran en un entorno virtual (Figura 1) representado por una caja de petri en la que los organismos compiten por el espacio y los recursos, se autoreplican y experimentan mutaciones. El usuario puede Figura 1. Captura de pantalla de Avida.

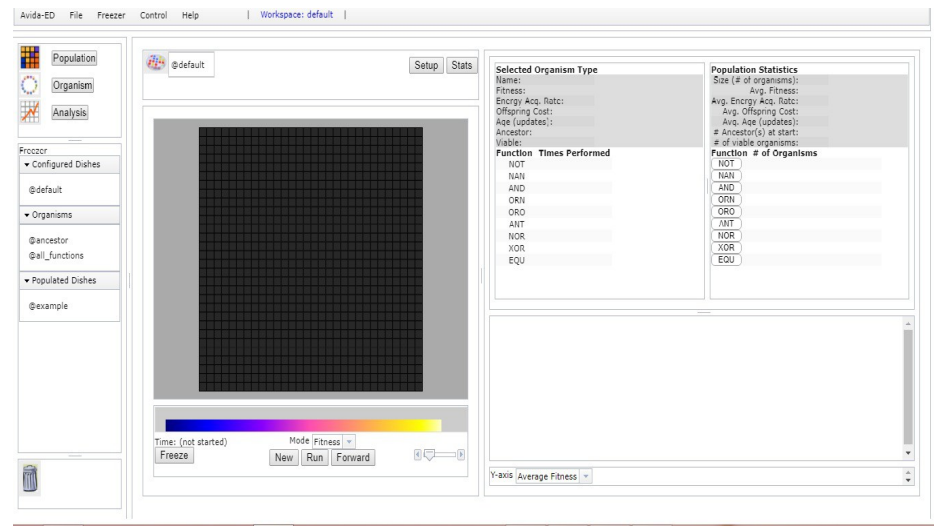
ajustar la tasa de mutación, la superficie de la caja de petri y los recursos que estarán disponibles en el ambiente.

Además puede agregar organismos adicionales antes, repetir con precisión las mutaciones producidas en algún organismo particular, colocar los organismos descendientes en la caja de petri y pausar o hacer correr el modelo. Si el usuario no modifica ninguna variable, igualmente los organismos experimentan una presión de selección implícita ya que los organismos que se muevan más rápido tendrán una ventaja. Avida permite diseñar y realizar experimentos con la finalidad de probar hipótesis sobre los mecanismos evolutivos utilizando la evolución digital de organismos.

\section{Cambios en el ambiente}

Esta simulación fue seleccionada a partir de 13 simulaciones que forman parte de un proyecto llamado "Evolution Readiness", puede bajarse de manera libre y gratuita desde https://learn.concord.org/evolutionreadiness. Permite a los estudiantes modificar las características del ambiente y observar el efecto de esos cambios en la supervivencia de

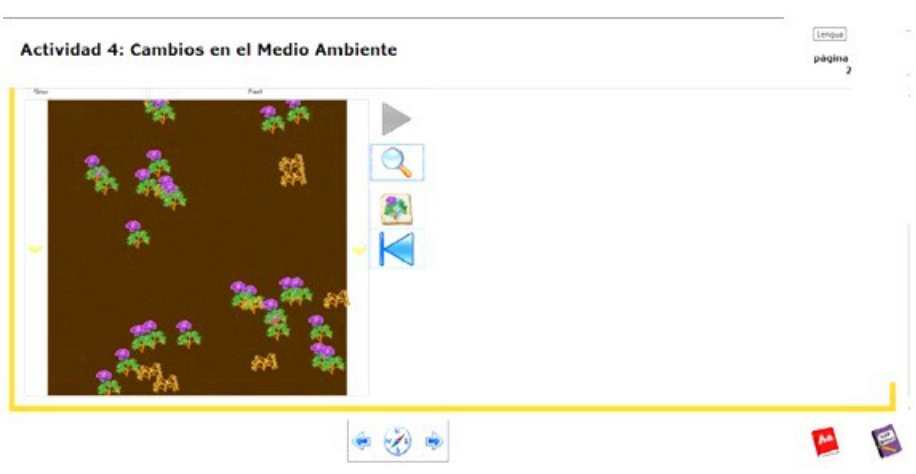
plantas con flores. El primerFigura 2. Captura de pantalla de Cambios en el Medio Ambiente. escenario (Figura 2), es un campo

virtual en donde el usuario debe plantar semillas haciendo clic sobre el icono correspondiente, también puede ajustar la velocidad de crecimiento de las plantas. En un segundo escenario el usuario puede modificar el ambiente introduciendo una cadena montañosa que atraviesa el campo a la mitad, modificar la altura de las montañas y la velocidad del crecimiento de las plantas. El objetivo de la simulación es lograr la supervivencia de las poblaciones de plantas a ambos lados de la cadena montañosa mientras se modifican las condiciones de luz solar al variar la altura de las montañas hasta su altura máxima. 


\section{El joc de 1'evolució}

Este juego desarrollado por la Fundación Catalana para la Investigación y la Innovación está disponible online en http://www.recercaenaccio.cat/jocs-irecursos-educatius/el-joc-de-levolucio/ En el primer escenario (Figura 3) se encuentra representado el tronco de un abedul de color claro, sobre el que se encuentran mariposas claras y oscuras. El usuario representa a un depredador insectívoro y debe capturar mariposas haciendo clic sobre ellas. Después de la segunda y tercera generación, las

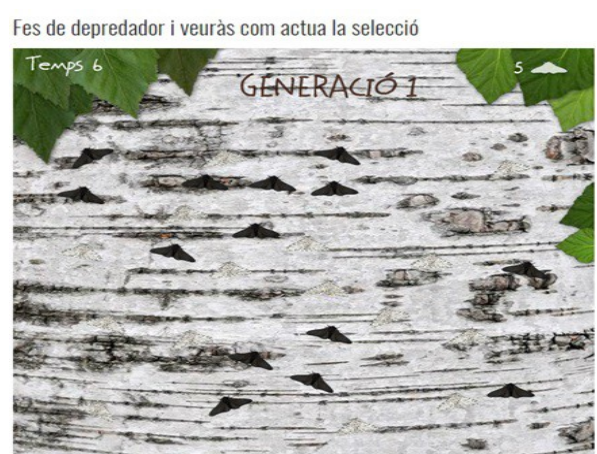

Figura 3. Captura de pantalla del joc de l' evolució. condiciones ambientales cambian y los abedules se tornan de color oscuro por la contaminación ambiental. Los usuarios nuevamente actúan como depredadores y deben capturar mariposas de la misma manera que en el primer escenario. Esta simulación brinda la posibilidad de visualizar la selección natural sobre mariposas de abedul, favoreciendo a las formas claras en un ambiente sin contaminación y a las formas oscuras en un ambiente contaminado.

\section{EvoluZion}

Esta simulación por computadora de procesos evolutivos (Zurita 2013) está disponible para descargar de manera libre y sin costo desde https://jevoluzion.jimdo.com/. En un primer escenario el usuario puede seleccionar los genes que van a mutar y los alelos que se van a analizar. Además puede ajustar el número inicial y máximo de organismos que van aparecer y los parámetros temporales $\mathrm{y} / \mathrm{o}$ ambientales. Durante la simulación el usuario puede agregar una toxina o provocar una catástrofe. El Figura 4. Captura de pantalla de EvoluZion.

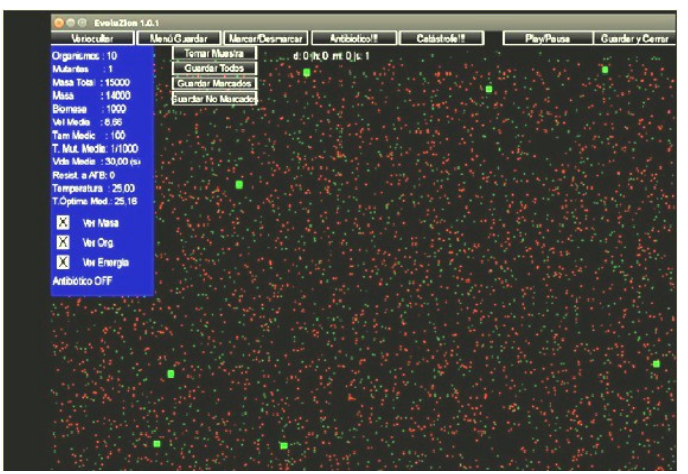
segundo escenario tiene forma de tablero (Figura 4), en el que se encuentran organismos representados por cuadrados verdes que comparten el espacio con círculos rojos (fuente de materia) y círculos verdes (fuente de energía). El usuario puede observar los cambios de color, de velocidad y de tamaño que los organismos adquieren con el tiempo.

\section{Gene Pool}

Esta simulación fue creada por J.J. Ventrella y se puede descargar de manera libre y sin costo desde http://www.swimbots.com/. En un primer escenario, el usuario puede establecer las características fenotípicas que resultarán ser las más atractivas para parejas potenciales, ajustar los niveles de energía y alimento y definir el contenido inicial de organismos. En un segundo escenario (Figura 5), los organismos virtuales llamados "swimbots" aparecen nadando en una

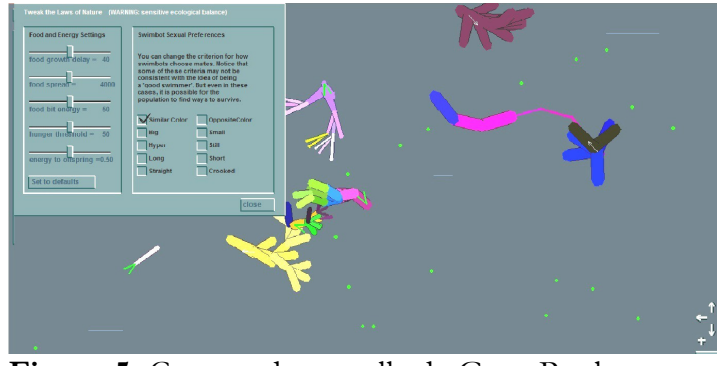

Figura 5. Captura de pantalla de Gene Pool. 
piscina virtual. El usuario puede mover algún organismo en particular para ayudarlo a sobrevivir, parar el modelo, visualizar en un gráfico el número de "swimbots" en función del tiempo, mover la cámara en $360^{\circ}$ y seleccionar a un organismo con alguna característica en particular o a la población completa. Gene Pool permite explorar cómo interviene el mecanismo de la selección natural en la supervivencia y reproducción de organismos virtuales.

\section{Jurassic World Evolution}

Es un producto comercial desarrollado por Frontier Development que puede ser adquirido en https://www.jurassicworldevolution.com/enGB\#masthead. El primer escenario (Figura 6) es una isla tridimensional en donde el usuario debe diseñar la construcción de un parque jurásico, construir instalaciones, caminos y miradores. En el segundo escenario el usuario puede modificar los "rasgos del genoma" de los dinosaurios y al presionar el botón "incubar", después de un

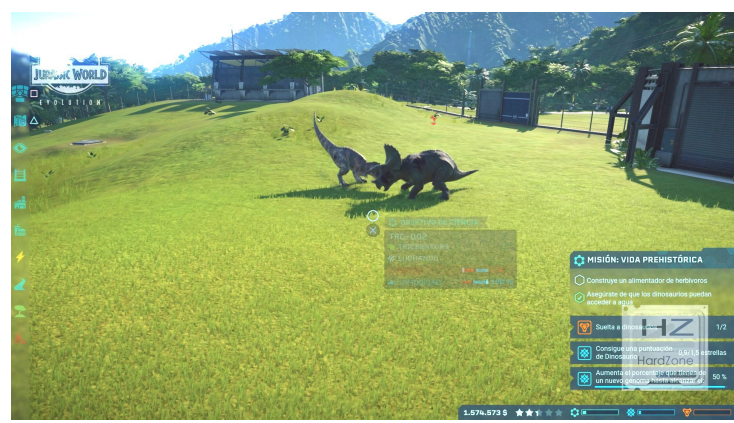
tiempo definido por el usuario, se crea el Evolution.

dinosaurio con las características seleccionadas y está listo para ser liberado al parque jurásico. A medida que avanza el juego la simulación permite modificar la constitución de los "rasgos genéticos" relacionados con las características comportamentales y/o los "rasgos estéticos" relacionados con las características físicas de los dinosaurios, para que puedan sobrevivir a las presiones de selección que se presentan en la isla. Este juego de estrategia permite a los usuarios realizar investigaciones genéticas para crear nuevas especies de dinosaurios, construir edificios y gestionar los distintos recursos de la isla "Nublar".

\section{Plague Inc: Evolved}

Es un juego desarrollado por Ndemic Creations que puede ser adquirido en https://www.ndemiccreations.com/en/25-plague-inc-evolved. En un primer escenario se encuentra representada una doble hélice de ADN y el jugador puede manipular el tipo de patógeno y la configuración genética del organismo insertando cuatro tipos de genes que están relacionados con las características metabólicas, nivel de resistencia a la cura, medio de dispersión, hábitat y costos energéticos de la transmisión del patógeno. En un segundo escenario (Figura 7) en donde se encuentra un mapa del mundo, el jugador debe seleccionar un lugar donde comience a propagarse la plaga y desde ese momento un contabilizador muestra el número de personas infectadas y muertas a medida que pasa el tiempo. Se brinda la posibilidad de modificar la configuración genética del patógeno para mejorarlo a medida que avanza el juego, seleccionando habilidades, forma de transmisión y síntomas producidos por el patógeno. El objetivo del juego es lograr diseñar un patógeno para extinguir a la

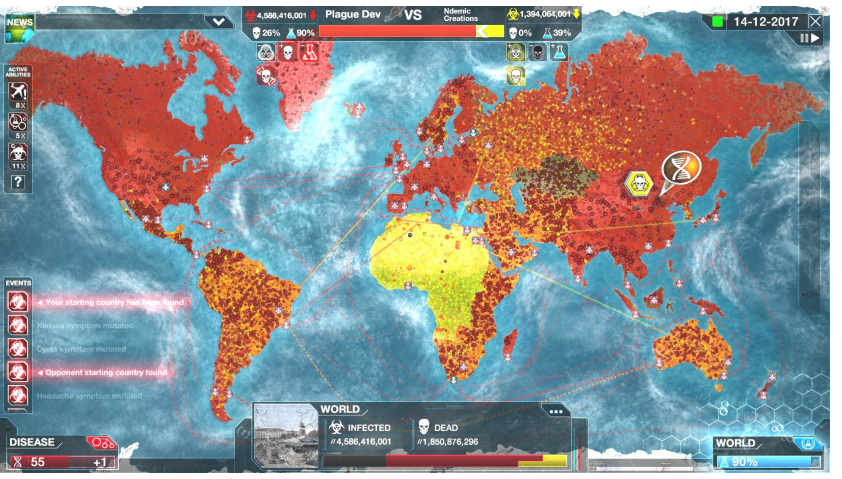
humanidad. 


\section{PopCycle}

Este software de simulación (Jon C. Herron) puede descargarse de manera gratuita desde http://faculty.washington.edu/herronjc/SoftwareFolder/software.html y forma parte de un grupo de aplicaciones para la enseñanza de la fie est evolución que han sido utilizadas como prototipos para ejercicios incluidos en el paquete EvoBeaker de SimBio. La simulación comienza con un escenario (Figura 8) en el que se encuentra una población de genes sobre la cual el usuario puede hacer clic y formar hasta 100 cigotos luego cliqueando el botón "hecho" para hacer crecer a los cigotos y visualizar gráficamente el número de cigotos, el número de

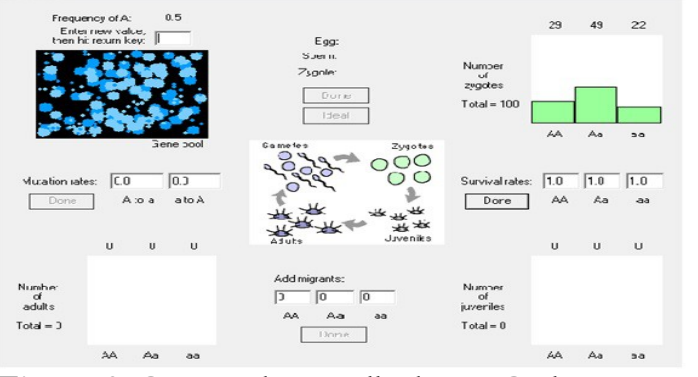

Figura 8. Captura de pantalla de PopCycle. juveniles y el número de adultos de cada genotipo (AA, Aa y aa). El usuario puede modificar la frecuencia del alelo A, la tasa de supervivencia de los cigotos, la tasa de mutación de los adultos y agregar juveniles inmigrantes. La modificación de estas variables permite poner a prueba distintas hipótesis, plantearse preguntas y explorar como actúa el mecanismo de la selección natural a nivel de gametas, cigoto, juveniles y adultos.

\section{Selección natural}

Forma parte de un proyecto de simulaciones interactivas de PhET de la Universidad de Colorado fundado por Carl Wieman y puede ser descargada de manera libre y gratuita desde https://phet.colorado.edu/es/simulations/category/biology. El escenario es una pradera donde se encuentran representados conejos y el usuario puede definir los factores de selección (Figura 9), las características de los conejos, el tipo de diagrama y hacer clic sobre los individuos para ver su genealogía o sobre el gráfico de número de individuos en función del tiempo para hacer zoom. Además, se puede agregar otro individuo para que se reproduzca con otro a través de una pestaña denominada "agregar un amigo".

A medida que avanza la simulación el número de conejos aumenta exponencialmente, siendo el objetivo de la simulación que el usuario agregue una presión de selección para evitar que el mundo colapse al ser totalmente invadido por conejos. Permite explorar cómo funciona el mecanismo de la selección natural al brindar la posibilidad de observar gráficamente cómo las características fenotípicas y genotípicas de una población de conejos afectan su capacidad de

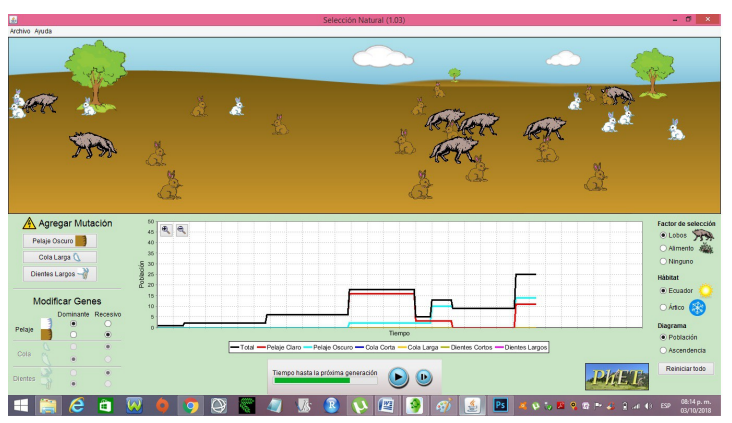
supervivencia y éxito reproductivo según las presiones de selección presentes en el ambiente.

\section{Spore}

Es un producto comercial (Electronic Arts 2008) que puede ser adquirido en www.spore.com, en donde también se puede descargar una versión gratuita de prueba. En un primer escenario se encuentra representado un organismo unicelular acuático en un océano virtual, producto de la colisión de un meteorito con la tierra. Aquí el usuario puede seleccionar el tamaño y la forma de alimentarse del organismo con el objetivo de lograr que el organismo se alimente y 
escape de sus depredadores para sumar puntos y de esta manera evolucionar hacia una forma terrestre. En un segundo escenario (Figura 10) el organismo se convierte en un animal terrestre que se encuentra en un bosque y el jugador puede modificar sus características fenotípicas a través de un proceso que trata de simular la reproducción sexual denominado "llamar a un compañero". En esta etapa el objetivo es

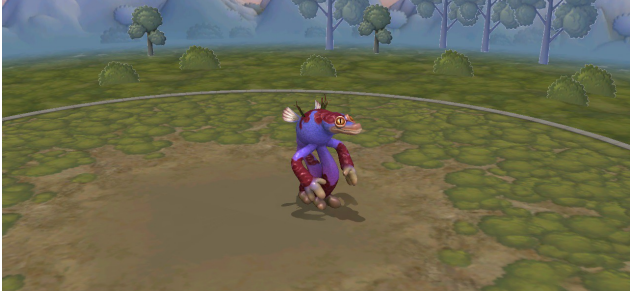

Figura 10 Captura de pantalla de Spore. lograr que las otras especies con las que se encuentre el organismo se extingan o entablar una relación con ellas.

\section{Resultados}

A continuación y respondiendo al objetivo de este trabajo, se presentan los resultados referidos al análisis de las simulaciones en función de las distintas dimensiones: aspectos técnicos, aspectos conceptuales y aspectos didácticos.

\section{Aspectos técnicos}

Cabe destacar que la mitad de las simulaciones requiere de conexión a Internet para funcionar, mientras que la otra mitad puede utilizarse sin conexión (Tabla 4). Solo tres simulaciones restringen su utilización a un ordenador mientras que el resto también permite el acceso a través de dispositivos móviles como consolas de videojuegos, celulares, tablets, etc. Todas las simulaciones analizadas en este estudio son de rápida instalación.

Tabla 4. Aspectos técnicos de las simulaciones

\begin{tabular}{|c|c|c|c|c|c|}
\hline Simulaciones & $\begin{array}{l}\text { Conexión } \\
\text { a Internet }\end{array}$ & $\begin{array}{l}\text { Software en los } \\
\text { que se puede } \\
\text { ejecutar }\end{array}$ & Idioma & $\begin{array}{l}\text { Calidad de los } \\
\text { componentes } \\
\text { visuales }\end{array}$ & $\begin{array}{l}\text { Funciones y /o material } \\
\text { extra }\end{array}$ \\
\hline AVIDA & No & $\begin{array}{l}\text { Windows Mac OS } \\
10.6\end{array}$ & Inglés & Baja & $\begin{array}{l}\text { Tutorial } \\
\text { Posibilidad de guardar las } \\
\text { actividades realizadas }\end{array}$ \\
\hline $\begin{array}{l}\text { Cambios en el } \\
\text { ambiente }\end{array}$ & Si & $\begin{array}{l}\text { Java launcher app } \\
(\text { OsX) Mavericks } \\
\text { (version } 10.9)\end{array}$ & $\begin{array}{l}\text { Español } \\
\text { Inglés }\end{array}$ & Baja & $\begin{array}{l}\text { Guía de actividades } \\
\text { Diccionario } \\
\text { Posibilidad de guardar las } \\
\text { actividades realizadas }\end{array}$ \\
\hline $\begin{array}{l}\text { El joc de } 1 \\
\text { evolució }\end{array}$ & Si & Java & Catalán & Baja & Menú informativo \\
\hline EvoluZion & $\mathrm{Si}$ & Java & $\begin{array}{l}\text { Español } \\
\text { Inglés }\end{array}$ & Baja & $\begin{array}{l}\text { Tutorial } \\
\text { Posibilidad de guardar las } \\
\text { actividades realizadas }\end{array}$ \\
\hline Gene Pool & No & $\begin{array}{l}\text { Windows } \\
\text { MacOsX, } \\
\text { iPad } \\
\text { Masintosh }\end{array}$ & $\begin{array}{l}\text { Inglés } \\
\text { Francés }\end{array}$ & Baja & $\begin{array}{l}\text { Tutorial } \\
\text { Posibilidad de guardar las } \\
\text { actividades realizadas }\end{array}$ \\
\hline $\begin{array}{l}\text { Jurassic World } \\
\text { Evolution }\end{array}$ & Si & $\begin{array}{l}\text { Windows } \\
\text { Phone } \\
\text { Ios } \\
\text { Android }\end{array}$ & $\begin{array}{l}\text { Español } \\
\text { Inglés } \\
\text { Francés } \\
\text { Portugués } \\
\text { Otros }\end{array}$ & Alta & Tutorial \\
\hline
\end{tabular}


Tabla 4. Continuación

\begin{tabular}{|c|c|c|c|c|c|}
\hline Simulaciones & $\begin{array}{l}\text { Conexión } \\
\text { a Internet }\end{array}$ & $\begin{array}{l}\text { Software en los que } \\
\text { se puede ejecutar }\end{array}$ & Idioma & $\begin{array}{l}\text { Calidad de los } \\
\text { componentes } \\
\text { visuales }\end{array}$ & $\begin{array}{l}\text { Funciones y /o material } \\
\text { extra }\end{array}$ \\
\hline $\begin{array}{l}\text { Plague Inc: } \\
\text { Evolved }\end{array}$ & $\mathrm{Si}$ & $\begin{array}{l}\text { Windows } \\
\text { Phone } \\
\text { Ios } \\
\text { Android }\end{array}$ & $\begin{array}{l}\text { Español } \\
\text { Inglés } \\
\text { Francés } \\
\text { Portugués } \\
\text { Otros }\end{array}$ & Alta & Tutorial \\
\hline PopCycle & No & Windows MacOSX & Inglés & Baja & Tutorial \\
\hline Selección natural & No & $\begin{array}{l}\text { Windows } \\
\text { XP/Vista/7/8.1/10, } \\
\text { última versión de Java. } \\
\text { Masintosh: OS X } \\
\text { 10.9.5 o posteriores } \\
\text { Linux }\end{array}$ & $\begin{array}{l}\text { Español } \\
\text { Inglés } \\
\text { Francés } \\
\text { Otros }\end{array}$ & Baja & $\begin{array}{l}\text { Tutorial } \\
\text { Posibilidad de guardar las } \\
\text { actividades realizadas }\end{array}$ \\
\hline Spore & $\mathrm{Si}$ & $\begin{array}{l}\text { Android:Android 4.1, } \\
\text { Windows XP:2.0 } \\
\text { Windows Vista- } 2.0 \\
\text { GHz P4 Mac: Mac OS } \\
\text { X 10.5.3 } \\
\text { Java launcher app } \\
\text { (OsX) }\end{array}$ & $\begin{array}{l}\text { Español } \\
\text { Inglés } \\
\text { Francés } \\
\text { Portugués } \\
\text { Otros }\end{array}$ & Alta & $\begin{array}{l}\text { Tutorial } \\
\text { Posibilidad de guardar las } \\
\text { actividades realizadas }\end{array}$ \\
\hline
\end{tabular}

En relación a la calidad de la interfaz gráfica, Plague Inc: Evolved, Jurassic World Evolution y Spore presentan una alta calidad caracterizada por incluir imágenes 3D con movimiento e interactivas dentro de un espacio tridimensional tal como se ejemplifica en las Figuras 6,7 y 10. Por su parte las siete simulaciones restantes presentan una calidad de interfaz gráfica baja con imágenes $2 \mathrm{D}$, que suelen ser interactivas dentro de un espacio bidimensional. La mayoría de las simulaciones seleccionadas están disponibles en inglés $(9 / \mathrm{N}=10)$ y tienen una versión en español $(6 / \mathrm{N}=10)$. También la mayoría de las simulaciones presentan funciones extras de interés, permiten guardar datos $(6 / \mathrm{N}=10)$ y disponen de un tutorial que explica su funcionamiento $(8 / \mathrm{N}=10)$, las cuales representan una ventaja práctica al momento de incorporar estos recursos en secuencias didácticas específicas.

En función de estas características registradas, se plantea como sugerencia para el profesorado evaluar antes de la selección del recurso, los software en los que se puede ejecutar, ya que ello determina la necesidad de trabajar con computadoras (personales o en una sala de informática específica) o si se puede plantear el trabajo en el aula con los dispositivos móviles del estudiantado. Además las simulaciones que permiten guardar las actividades realizadas brindan la posibilidad de continuar el trabajo en otro momento, así como también utilizar la información de la simulación para elaborar informes o presentaciones. En particular Cambios en el ambiente ofrece una guía de actividades orientadas a que los estudiantes analicen lo que sucede en la simulación cuando modifican las variables del ambiente y un diccionario con términos específicos relacionados con los fenómenos biológicos representados en la simulación. De utilizarse esta simulación se sugiere realizar una puesta en común de las respuestas registradas por cada estudiante en la simulación al finalizar cada etapa.

Por otra parte la alta calidad de los componentes visuales podría favorecer el interés del estudiantado, por lo que se sugiere tomar en consideración este aspecto en el momento de la selección. Por último, en los casos en los que el idioma en que se encuentra disponible cada simulación no coincide con la lengua del estudiantado se podrían desarrollar propuestas de trabajo interdisciplinarias con las asignaturas de idiomas. 


\section{Aspectos conceptuales}

Se identifica que las simulaciones Evoluzion y Gene Pool permiten observar en tiempo real cómo los organismos, que se representan con símbolos no específicos, se reproducen, desarrollan, compiten por los recursos y cambian su fenotipo (Tabla 5). Esto supone una ventaja ya que el usuario puede diferenciar claramente los distintos fenómenos biológicos implicados en la evolución. Además permiten identificar las características genotípicas y fenotípicas de las distintas generaciones, incorporan al azar como fuente de variación y a las variables que definen la aptitud de los individuos como la tasa de supervivencia, la variabilidad genética y la tasa de reproducción. Cabe destacar que Evoluzion y Gene Pool representan la variabilidad genética y fenotípica entre individuos de una misma población y esto podría favorecer en los estudiantes el desarrollo de un pensamiento poblacional el cual es fundamental para la comprensión del MESN (Hernández, Álvarez Pérez y Ruiz Gutiérrez 2009). Es por ello que en Evoluzion y Gene Pool se infiere un alto nivel de ajuste al modelo conceptual de evolución por selección natural ya que incorporan sus principios fundamentales (Lewontin 1970, Horwitz 2013). En particular Gene Pool (Figura 5) utiliza organismos que evolucionan modificando completamente su forma, esta manera de representar la evolución podría favorecer la superación del obstáculo esencialista en el sentido de mostrar cómo una especie puede modificarse en otra mediante la evolución. Las simulaciones Avida y PopCycle se diferencian del resto porque la selección ocurre a nivel de genes lo cual permite visualizar que este mecanismo opera no solo sobre los organismos adultos sino también sobre otros estadios de desarrollo (Dawkins 1976).

Tabla 5. Aspectos conceptuales de las simulaciones

\begin{tabular}{|c|c|c|c|c|}
\hline Simulaciones & Tipo de modelo & $\begin{array}{l}\text { Variables y/o factores } \\
\text { incluidos en el modelo }\end{array}$ & $\begin{array}{l}\text { Nivel de } \\
\text { selección }\end{array}$ & Organismo modelo \\
\hline AVIDA & $\begin{array}{l}\text { Continuo } \\
\text { Estocástico }\end{array}$ & $\begin{array}{l}\text { Tasa de mutación } \\
\text { Variabilidad genética } \\
\text { Variabilidad fenotípica } \\
\text { Constitución genética } \\
\text { Número de individuos } \\
\text { Número de generaciones } \\
\text { Presiones selectivas }\end{array}$ & Población & Símbolo no específico \\
\hline Cambios en el ambiente & $\begin{array}{l}\text { Discreto } \\
\text { Determinista }\end{array}$ & $\begin{array}{l}\text { Cambio fenotípico } \\
\text { Presiones selectivas }\end{array}$ & Población & $\begin{array}{l}\text { Entidad biológica } \\
\text { reconocida }\end{array}$ \\
\hline El joc de l'evolució & $\begin{array}{l}\text { Discreto } \\
\text { Determinista }\end{array}$ & $\begin{array}{l}\text { Cambio fenotípico } \\
\text { Número de generaciones } \\
\text { Presiones selectivas }\end{array}$ & Población & $\begin{array}{l}\text { Entidad biológica } \\
\text { reconocida }\end{array}$ \\
\hline Gene Pool & $\begin{array}{l}\text { Continuo } \\
\text { Estocástico }\end{array}$ & $\begin{array}{l}\text { Tasa de mutación } \\
\text { Tasa de migración } \\
\text { Tasa de supervivencia } \\
\text { Variabilidad fenotípica } \\
\text { Variabilidad genética } \\
\text { Número de individuos } \\
\text { Número de generaciones } \\
\text { Cambio fenotípico } \\
\text { Presiones selectivas }\end{array}$ & Población & Símbolo no específico \\
\hline
\end{tabular}


Tabla 5. Continuación

\begin{tabular}{|c|c|c|c|c|c|}
\hline Simulaciones & Tipo de modelo & $\begin{array}{l}\text { Variables y/o factores } \\
\text { incluidos en el modelo }\end{array}$ & $\begin{array}{l}\text { Nivel de } \\
\text { selección }\end{array}$ & \multicolumn{2}{|c|}{ Organismo modelo } \\
\hline $\begin{array}{ll}\text { Jurassic } & \text { World } \\
\text { Evolution } & \end{array}$ & $\begin{array}{l}\text { Discreto } \\
\text { Determinista }\end{array}$ & $\begin{array}{l}\text { Constitución genética } \\
\text { Cambio fenotípico } \\
\text { Presiones selectivas }\end{array}$ & Individuo & $\begin{array}{l}\text { Entidad } \\
\text { reconocida }\end{array}$ & biológica \\
\hline Plague Inc: Evolved & $\begin{array}{l}\text { Discreto } \\
\text { Determinista }\end{array}$ & $\begin{array}{l}\text { Constitución genética } \\
\text { Cambio fenotípico } \\
\text { Presiones selectivas }\end{array}$ & Población & $\begin{array}{l}\text { Entidad } \\
\text { reconocida }\end{array}$ & biológica \\
\hline PopCycle & $\begin{array}{l}\text { Discreto } \\
\text { Determinista }\end{array}$ & $\begin{array}{l}\text { Tasa de mutación } \\
\text { Tasa de migración } \\
\text { Tasa de supervivencia } \\
\text { Variabilidad genética }\end{array}$ & $\mathrm{P}$ & $\begin{array}{l}\text { Entidad } \\
\text { reconocida }\end{array}$ & biológica \\
\hline Spore & $\begin{array}{l}\text { Discreto } \\
\text { Determinista }\end{array}$ & $\begin{array}{l}\text { Constitución genética } \\
\text { Cambio fenotípico } \\
\text { Presiones selectivas }\end{array}$ & Individuo & Avatar & \\
\hline
\end{tabular}

Otras simulaciones como Cambios en el ambiente, El joc de l'evolució y Selección natural muestran cómo ocurre la evolución pero no incorporan muchos de los factores y/o variables que intervienen en este proceso. En estas simulaciones una población, representada por un conjunto de entidades biológicas reconocidas, presenta ciertas características fenotípicas que cambian en respuesta a las presiones del ambiente. Es decir que no incluyen al azar como fuente de variación y utilizan solo la adaptación para explicar la evolución por selección natural a pesar de que en el modelo científico de evolución por selección el azar resulta fundamental e intervienen múltiples fenómenos biológicos (Gould 2002).

Además estas simulaciones podrían fortalecer concepciones alternativas asociadas a explicaciones finalistas. Por otro lado, al representarse los cambios fenotípicos de los individuos como variaciones en su color sin mostrar modificaciones estructurales que indiquen que una especie se modifica en otra se podrían fortalecer concepciones alternativas asociadas a obstáculos epistemológicos del tipo esencialista (Pérez, Gómez Galindo y González-Galli 2018). En Cambios en el ambiente y El joc de l'evolució no se incluye la variabilidad genética y/o constitución genética de los organismos, lo cual podría conducir a que los estudiantes interpreten a la evolución sin tener en cuenta la base genética de este proceso siendo esta fundamental para la comprensión de la teoría de la evolución por selección natural. Jurassic World Evolution, Plague Inc: Evolved y Spore incluyen la variabilidad genética pero se caracterizan por representar los cambios fenotípicos en un solo individuo el cual se representa por una entidad biológica reconocida o Avatar. Esto podría funcionar como un obstáculo de aprendizaje al mostrar que la evolución ocurre a nivel individuo y no a nivel poblacional.

En la Tabla 6 se realizan sugerencias para la utilización de cada una de las simulaciones, se indican los contenidos que permite abordar y se proporcionan consideraciones de vigilancia epistemológica para la elaboración de secuencias didácticas que integren estos recursos en la enseñanza del MESN. 
Tabla 6. Sugerencias de vigilancia epistemológica para la utilización de cada una de las simulaciones

\begin{tabular}{|c|c|}
\hline Simulaciones & Sugerencias \\
\hline Avida & $\begin{array}{l}\text { Esta simulación podría ser utilizada para abordar la base genética del proceso de evolución } \\
\text { por selección natural. Se sugiere incluir conceptos como tasa de mutación, variabilidad } \\
\text { genética, metabolismo y fitness en actividades que permitan a los estudiantes identificar y } \\
\text { reflexionar sobre el rol que juega la genética en el proceso de evolución por selección natural. }\end{array}$ \\
\hline $\begin{array}{ll}\text { Cambios en el } \\
\text { ambiente }\end{array}$ & $\begin{array}{l}\text { En esta simulación los estudiantes pueden observar cómo ocurre la adaptación de los } \\
\text { organismos al ambiente, es necesario que los docentes complementen la guía de actividades } \\
\text { que propone la simulación con actividades que permitan a los estudiantes diferenciar la } \\
\text { adaptación del proceso de evolución biológica por selección natural y comprender la base } \\
\text { genética de la evolución. }\end{array}$ \\
\hline $\begin{array}{ll}\text { El joc de } & 1 \\
\text { 'evolució } & \\
& \end{array}$ & $\begin{array}{l}\text { Podría generar en los estudiantes una noción de intencionalidad de la selección natural por el } \\
\text { hecho de que deben hacer clic sobre las mariposas en su rol de depredador, motivo por el } \\
\text { cual se sugiere complementar el uso de esta simulación con preguntas y/o actividades } \\
\text { orientadas a identificar cómo interviene el azar en el proceso de evolución por selección } \\
\text { natural. Además se sugiere proponer actividades que permitan reconocer la base genética de } \\
\text { este proceso. }\end{array}$ \\
\hline EvoluZion & $\begin{array}{l}\text { Esta simulación incluye la mayoría de las variables que intervienen en el proceso de evolución } \\
\text { biológica por selección natural y además incorpora la deriva génica como posible mecanismo } \\
\text { de evolución. Se recomienda utilizar este recurso con estudiantes que ya tengan } \\
\text { conocimientos en evolución con la intención de profundizar y/o analizar los distintos } \\
\text { aspectos del MESN y diferenciar la selección natural de la deriva génica como posibles } \\
\text { mecanismos de evolución. }\end{array}$ \\
\hline Gene Pool & $\begin{array}{l}\text { Se identifica que esta simulación aparte de las principales variables del MESN incluye } \\
\text { aspectos vinculados con la selección sexual. Este tipo de selección si bien es considerada } \\
\text { como un tipo de selección natural requiere comprender conceptos asociados como } \\
\text { reproducción diferencial, reproducción sexual y asexual, recombinación genética etc., por lo } \\
\text { que se recomienda planificar secuencias didácticas en las que se trabajen estos conceptos con } \\
\text { los estudiantes antes de utilizar la simulación. }\end{array}$ \\
\hline $\begin{array}{l}\text { Jurassic World } \\
\text { Evolution } \\
\end{array}$ & $\begin{array}{l}\text { En este juego de simulación los cambios genéticos y fenotípicos en respuesta a los cambios } \\
\text { del ambiente se producen a nivel individuo y no se incluye al azar, motivo por el cual se } \\
\text { requiere planificar actividades que permitan desarrollar el pensamiento poblacional y la } \\
\text { manera en la que interviene el azar en el MESN. Además se sugiere proponer preguntas que } \\
\text { permitan problematizar cómo se representa la evolución en la simulación y que los } \\
\text { estudiantes puedan identificar los errores conceptuales que incluye este recurso. }\end{array}$ \\
\hline $\begin{array}{l}\text { Plague } \\
\text { Evolved }\end{array}$ & $\begin{array}{l}\text { En relación a este juego se identifica que podría favorecer a que se construya un concepto } \\
\text { equivocado pensando a la evolución como proceso que busca mejorar a los individuos de una } \\
\text { población, ya que en el escenario del juego se debe "mejorar" al virus para que pueda } \\
\text { extinguir a toda la humanidad. Se sugiere plantear situaciones en las que los estudiantes } \\
\text { puedan problematizar esta noción de evolución identificando el rol que cumple el azar en este } \\
\text { proceso y superar esta idea que dificulta la comprensión del MESN. }\end{array}$ \\
\hline PopCycle & $\begin{array}{l}\text { Esta simulación podría ser utilizada como un recurso para introducir el contenido evolución } \\
\text { por selección natural ya que está centrada en la evolución a nivel de genes. Se sugiere } \\
\text { complementar el uso de esta simulación con preguntas y/o actividades que permitan a los } \\
\text { estudiantes reconocer la base genética del proceso de evolución por selección natural. }\end{array}$ \\
\hline Selección natural & $\begin{array}{l}\text { En esta simulación educativa se representan las principales variables que influyen en la } \\
\text { evolución por selección natural pero no se incluye el azar como fuente de variación y los } \\
\text { cambios fenotípicos son representados por pequeños cambios morfológicos. Se recomienda } \\
\text { diseñar secuencias didácticas en las que se problematicen estas cuestiones, aportando } \\
\text { ejemplos de macroevolución y explicitando el rol del azar en la evolución biológica. }\end{array}$ \\
\hline Spore & $\begin{array}{l}\text { Para esta simulación se requiere planificar actividades en las que los estudiantes puedan } \\
\text { identificar como un error conceptual que la evolución aquí está representada a nivel individuo } \\
\text { y reflexionar acerca del rol fundamental que cumple el azar y el tiempo en la evolución } \\
\text { (ambos aspectos no incluidos en el juego). }\end{array}$ \\
\hline
\end{tabular}




\section{Aspectos didácticos}

El nivel de manipulación identificado (por la integrante del grupo de investigación que navegó estos recursos) fue alto para seis de las simulaciones, presentando oportunidades para manipular cuatro o más variables del sistema, mientras que solo la simulación El joc d' le evolució presentó un nivel bajo de manipulación ya que ofrece un escenario en el cual se puede manejar una variable (Tabla 7). A su vez, también El joc d' le evolució fue la única simulación que presentó un recorrido cerrado proponiendo un solo itinerario posible. De manera que en esta simulación el rol del usuario está centrado principalmente en recibir información. Por el contrario, la mitad de las simulaciones $(5 / \mathrm{N}=10)$ presentó recorridos abiertos incluyendo cuatro o más itinerarios para optar. En cuanto a la retroalimentación proporcionada por las simulaciones, se destaca que siete presentaron un nivel alto brindando la posibilidad de visualizar de manera gráfica o numérica cómo cambia el modelo cuando se modifica el valor de las variables.

Por último, al considerar de modo conjunto el nivel de manipulación de variables, el recorrido propuesto y la retroalimentación proporcionada al usuario encontramos que AVIDA, EvoluZion y Gene Pool ofrecen recorridos que podrían mediar la comprensión del MESN fomentando el desarrollo de prácticas científicas. En efecto, estas tres simulaciones brindan oportunidades para que el usuario se plantee hipótesis vinculadas a las variables del modelo, las modifique, observe y analice los cambios que se producen en el sistema simulado y en función de ello evalúe su hipótesis inicial (Develaki 2017). Esta posibilidad de testear hipótesis que brindan las simulaciones resulta de particular interés para el MESN ya que la naturaleza de los procesos evolutivos impide que en un contexto educativo se puedan desarrollar experimentos o tomar datos de modo directo con el fenómeno de estudio. A su vez, en el ámbito científico para la producción de conocimiento en el campo de la evolución también se ponen en juego simulaciones computacionales. Por lo tanto, estas simulaciones permitirían crear escenarios de aprendizaje más cercanos a la propia naturaleza de este conocimiento científico (Develaki 2019).

Tabla 7. Aspectos didácticos de las simulaciones

\begin{tabular}{|l|l|l|l|l|}
\hline Simulaciones & $\begin{array}{l}\text { Nivel de } \\
\text { manipulación } \\
\text { de variables }\end{array}$ & Recorridos propuestos & $\begin{array}{l}\text { Orientación } \\
\text { al usuario }\end{array}$ & $\begin{array}{l}\text { Retroalimentación } \\
\text { proporcionada } \\
\text { usuario }\end{array}$ \\
\hline AVIDA & Alto & Abierto & Semiguiado & Alta \\
\hline Cambios en el ambiente & Medio & Semiabierto & Semiguiado & Alta \\
\hline El joc de l'evolució & Bajo & Cerrado & Intuitivo & Baja \\
\hline EvoluZion & Alto & Abierto & Intuitivo & Alta \\
\hline Gene Pool & Alto & Abierto & Semiguiado & Alta \\
\hline Jurassic World Evolution & Alto & Abierto & Semiguiado & Alta \\
\hline Plague Inc: Evolved & Alto & Semiabierto & Semiguiado & Baja \\
\hline PopCycle & Alto & Abierto & Semiguiado & Alta \\
\hline Selección natural & Bajo & Semiabierto & Intuitivo & Alta \\
\hline Spore & Bajo & Semiabierto & Guiado & Baja \\
\hline
\end{tabular}

En función de los objetivos que se planteen para el trabajo con estos recursos, aportamos algunas sugerencias. Aquellas simulaciones que presentan un alto nivel de manipulación de variables con alta retroalimentación permiten trabajar prácticas científicas como el planteo y evaluación de hipótesis así como también la argumentación. Para ello sugerimos que durante 
el juego el estudiantado registre las decisiones que va tomando y la retroalimentación que recibe a partir de ellas. Luego del uso de la simulación, esta información puede ser utilizada como insumo para desarrollar reflexiones metacognitivas acerca de los recorridos realizados, las hipótesis construidas y su evaluación. Las simulaciones que presentan menor nivel de manipulación pueden incorporarse con otros objetivos de aprendizaje ya que de todos modos ofrecen la posibilidad de visualizar procesos abstractos en un escenario dinámico. Para este tipo de recursos se sugiere reflexionar con el estudiantado acerca de cuáles serían las posibilidades que no se encuentran simuladas y cuáles son las limitaciones de aquello que sí está representado.

\section{Conclusión}

En este trabajo nos propusimos aportar una caracterización de las simulaciones del proceso de evolución biológica, con la finalidad de evaluar su potencial para la enseñanza del MESN. En función de ello describimos diez simulaciones, las analizamos considerando sus aspectos técnicos, conceptuales y didácticos y ofrecimos aportes para pensar su incorporación en diseños didácticos. A partir de los datos obtenidos encontramos que algunas de las simulaciones presentan potencialidades para trabajar diferentes aspectos del MESN mientras que otras podrían fortalecer concepciones alternativas asociadas a obstáculos epistemológicos que dificultan la comprensión de la teoría de la evolución por selección natural.

Algunas simulaciones que podrían fortalecer concepciones alternativas asociadas a obstáculos epistemológicos que dificultan la comprensión de la teoría de la evolución por selección natural son Cambios en el ambiente, El joc de l'evolució y Selección natural. Los principales aspectos que colocan a estas simulaciones en este lugar son la exclusión del azar como fuente de variación y la simplificación de la explicación de la evolución a la adaptación (Gould 2002). Además podrían fortalecer concepciones alternativas asociadas a explicaciones finalistas. Por su parte, Jurassic World Evolution, Plague Inc: Evolved y Spore también podrían fomentar concepciones alternativas asociadas a obstáculos epistemológicos al mostrar que la evolución ocurre a nivel individuo y no a nivel poblacional.

Por el contrario, en relación a aquellas simulaciones que presentan potencialidades para la enseñanza del MESN, queremos destacar a EvoluZion y Gene Pool. Ambas utilizan modelos que incorporan múltiples fenómenos biológicos para explicar el proceso de evolución biológica, representan la variabilidad genética y fenotípica de los individuos de una misma población e incluyen al azar como fuente de variación. Además permiten testear hipótesis y ofrecen recorridos abiertos lo cual implica que las hipótesis pueden variar según cada estudiante obteniendo así diferentes respuestas del sistema simulado. A partir de estas respuestas se podría solicitar al estudiantado que argumente la validez de sus hipótesis, ofreciendo así oportunidades para desarrollar habilidades del pensamiento científico. Por lo tanto, consideramos que estas simulaciones presentan características de interés que las colocan como potenciales favorecedoras de la comprensión del MESN y podrían integrase en recorridos didácticos que impliquen prácticas científicas de alto valor epistémico.

Retomando los aportes de Alzugaray, Carreri y Marino (2009) quienes destacan que la inclusión de las tecnologías debe estar acompañada por una reflexión pedagógico didáctica, consideramos que la caracterización aportada por este estudio brinda información específica que podría ser de utilidad para docentes que deseen incorporar estas simulaciones en sus diseños didácticos, así como también para investigadores interesados en el estudio didáctico de estos recurso. En este sentido, consideramos que si bien Plague Inc: Evolved podría fortalecer concepciones alternativas asociadas a obstáculos epistemológicos, presenta algunas 
características de interés. Este recurso exhibe un alto nivel en sus componentes visuales y en la manipulación de variables, incorpora a la genética como base de la evolución biológica y se basa en el planteo de una situación problemática que podría estar relacionada con los intereses del estudiantado. Por lo tanto, se podría integrar a Plague Inc: Evolved en diseños didácticos que incluyan actividades específicas de reflexión y discusión acerca de cómo actúa la evolución a nivel poblacional y de cómo este proceso es representado por la simulación.

Por último, entendemos que para conocer de qué manera intervienen en la comprensión del MESN cada una de estas simulaciones se requiere estudiar específicamente la integración de las simulaciones en diseños didácticos y su práctica áulica. Consideramos que esta línea de trabajo presenta nuevas oportunidades para la construcción de conocimiento didáctico en el campo de la educación en evolución.

\section{Agradecimientos}

Al Dr. Santiago Benítez-Vieyra y al Grupo de Investigación EDUCEVA-CienciaTIC por sus aportes y sugerencias. A la Secretaría de Ciencia y Técnica de la Universidad Nacional de Córdoba y a CONICET por su aporte económico para la realización de este trabajo.

\section{Referencias Bibliográficas}

Adúriz-Bravo A. y Ariza Y. (2014) Una caracterización semanticista de los modelos científicos para la ciencia escolar. Bio-grafia: escritos sobre la biología y la enseñanza 7(13), 25-34.

Agusti J. (2010). El ajedrez de la vida. Editorial Crítica.

Alzugaray G.E., Carreri R.A., Marino L.A. (2009) Aportes del laboratorio virtual al aprendizaje del campo y potencial eléctrico. Memorias de la XVI Reunión Nacional de Educación en la Física. San Juan, Argentina. http://dea.unsj.edu.ar/said/FILES/p70.pdf

Ardura D., Zamora A. (2014) ¿Son útiles entornos virtuales de aprendizaje en la enseñanza de las ciencias secundaria? Evaluación de una experiencia en la enseñanza y el aprendizaje de la Relatividad. Revista Eureka sobre Enseñanza y Divulgación de las Ciencias 11 (1), 83-93. https://revistas.uca.es/index.php/eureka/article/view/2864

Azcárraga J.A. (2009) Vigencia y actualidad de la teoría de la evolución: reflexiones en el bicentenario de Darwin. Revista Real Academia de Ciencias de Zaragoza 64, 65-105. https://www.uv.es/ azcarrag/pdf/2009 Rev. Acad. Zgza 64, 65-107 (2009).pdf

Bardin L. (1986) Análisis de Contenido. Madrid: Akal.

Bermúdez G. (2015) Los orígenes de la Biología como ciencia. El impacto de las teorías de evolución y las problemáticas asociadas a su enseñanza y aprendizaje. Revista Eureka sobre Enseñanza y Divulgación de las Ciencias 12 (1), 66-90. https://revistas.uca.es/index.php/eureka/article/view/290 3

Cataldi Z., Lage F.J., Dominighini F.C. (2013) Fundamentos para el uso de simulaciones en la enseñanza. Revista de Informática Educativa y Medios Audiovisuales 10 (17), 8-16. http://laboratorios.fi.uba.ar/lie/Revista/Articulos/101017/A2mar2013.pdf

Contreras-Gelves G.A., Carreño Moreno P. (2012) Simuladores en el ámbito educativo: un recurso didáctico para la enseñanza. INGENIUM Revista de la Facultad de Ingeneiría 13 (25), 107-119.

Dawkins R. (1976) El gen egoísta. Oxford: Oxford University Press.

De Jong T., Linn M.C., Zacharia Z.C. (2013) Physical and virtual laboratories in science and engineering education. Science 340, 305-308. 
Develaki M. (2017) Using Computer Simulations for Promoting Model-based Reasoning. Epistemological and Educational Dimensions. Science \& Education 26 (7-9), 1001-1027.

Develaki M. (2019) Methodology and Epistemology of Computer Simulations and Implications for Science Education. Journal of Science Education and Technology 28 (4), 353370 .

Estebanell Minguell M. (2002) Interactividad e Interacción. Revista Latinoamericana de Tecnología Educativa (RELATEC) 1 (1), 23-32.

Evagorou M., Erduran S., Mäntylä T. (2015) The role of visual representations in scientific practices: from conceptual understanding and knowledge generation to 'seeing' how science works. International Journal of STEM Education 2 (11).

Fernández-Cesar R., Aguirre-Pérez C. (2012) ¿Mejoran las simulaciones en los laboratorios de química el aprendizaje de los alumnos? Percepciones de alumnos universitarios de primer curso de Quimica General. Revista Eureka sobre Enseñanza y Divulgación de las Ciencias 10 (1), 47-65.https:// revistas.uca.es/index.php/eureka/article/view/2793

Folguera G., Gonzalez-Galli L. (2012). La extensión de la síntesis evolutiva y los alcances sobre la enseñanza de la teoría de la evolución. Biografia: Escritos sobre biología y su enseñanza 5 (9), 4-18.

Garcia-Romano L., Occelli M. (2019). Un modelo analítico para caracterizar recursos tecnológicos basados en contenidos científicos. Revista de Enseñanza de la Física 31 (1), 15-25. https://revistas.unc.edu.ar/index.php/revistaEF/article/view/24667

Garófalo S.J., Chemes L.B., Alonso M. (2016) Propuesta didáctica de enseñanza con simulaciones para estudiantes del profesorado en Ciencias Biológicas. Revista Eureka sobre Enseñanza y Divulgación de las Ciencias 13 (2), 359-372. https://revistas.uca.es/index.php/eureka/article/view/2972

Giere R.N. (2005). Scientific Realism: Old and new problems. Erkenntnis 1-18.

González-Galli L., Adúriz-Bravo A., Meinardi E. (2005) El modelo cognitivo de ciencia y los obstáculos en el aprendizaje de la evolución biológica. Enseñanz̧a de las Ciencias Número Extra.

González-Galli L., Meinardi S. (2015) Obstáculos para el aprendizaje del modelo de evolución por selección natural, en estudiantes de escuela secundaria de la Argentina. Ciencias \& Educação 21 (1), 101-122.

González -Galli L., Meinardi S. (2017) Obstáculos para el aprendizaje del modelo de evolución por selección natural, en estudiantes universitarios de biología. Revista Eureka sobre Enseñanza y Divulgación de las Ciencias $14 \quad$ (3), 435-449. https://revistas.uca.es/index.php/eureka/article/view/3502

Gould S.J. (2002) La estructura de la teoría de la evolución. Colección Metatemas. Barcelona: Tusquets Editores.

Hernández M.C., Álvarez Pérez E., Ruiz Gutiérrez R. (2009) La selección natural: aprendizaje de un paradigma. Teorema 28 (2), 107-121.

Herrero D., del Castillo H., Monjelat N., García-Varela A.B., Checa M., Gómez P. (2014) La teoría de la evolución y la selección natural: aprender a través del juego y la reflexión. New Approaches in Educational Research 3 (1), 28-35. 
Horwitz P. (2013) Evolution is a model, Why not teach it that way? En C. Tsui, F. Treagust (Eds.), Multiple Representations in Biological Education. New York: Springer, 129-145.

Lewontin R.C. (1970).The units of selection. Annual Review of Ecology and Systematics. 1, 1-18. https://doi.org/10.1146/annurev.es.01.110170.000245

Lombardi O. (2010). Capítulo 4: Los modelos como mediadores entre teoría y realidad. En: L. Galagovsky (Comp.), Didáctica de las Ciencias Naturales. El caso de los modelos científicos. Buenos Aires: Lugar Editorial. S.A.

Occelli M., Garcia Romano L. (2018) Las simulaciones en la enseñanza de la Biología. Docentes conectados 1 (1), 3-16.

Occelli M., Malin Vilar T. (2018) Capítulo 13: Los videojuegos ¿un problema de distracción o una oportunidad para aprender? En M. Occelli, L. Garcia Romano, N. Valeiras, M. Quintanilla (Comp.), Las tecnologías de la información y la comunicación como berramientas mediadoras de los procesos educativos. Volumen I: Fundamentos y Reflexiones Santiago de Chile: Editorial Bellaterra Ltda http://www.inv.educeva.efn.uncor.edu/?page_id=341

Ortiz F., Piña C. (2018) Estrategia tecno-didáctica para la solución de problemas de genética en estudiantes de educación a distancia. Revista Eureka sobre Enseñanza y Divulgación de las Ciencias 15(2),2301.doi: 10.25267/Rev_Eureka_ensen_divulg_cienc.2018.v15.i2.2301

Pérez G., Gómez Galindo A. , González-Galli L. (2018) Enseñanza de la evolución: fundamentos para el diseño de una propuesta didáctica basada en la modelización y la metacognición sobre los obstáculos epistemológicos. Revista Eureka sobre Enseñanza y $\begin{array}{lllll}\text { Divulgación de las } & \text { Ciencias } & 15 & \text { (2), } & 2102 .\end{array}$ https://doi.org/10.25267/Rev_Eureka_ensen_divulg_cienc.2018.v15.i2.2102

Pessanha M., Pietrocola M., Couso D. (2013) Obstáculos epistemológicos no estudo de modelos atômicos com o uso de simulações computacionais. In: XX Simpósio Nacional de Ensino de Física, 2013, São Paulo.

Pontes A. (2005) Aplicaciones de las tecnologías de la información y de la comunicación en la educación científica. Primera parte: funciones y recursos. Revista Eureka sobre Enseñanz̨a y Divulgación de las Ciencias 2 (1), 2-18. https://revistas.uca.es/index.php/eureka/article/view/3930

Rivas M.L., González García F. (2016) ¿Comprenden y aceptan los estudiantes la evolución? Un estudio en bachillerato y universidad. Revista Eureka sobre Enseñanza y Divulgación de las Ciencias 13 (2), 248-263.

Riveros V., Mendoza M.I. (2005) Bases teóricas para el uso de las TIC en educación. Encuentro Educacional $12 \quad$ (3), 315-336. https://revistas.uca.es/index.php/eureka/article/view/2966

Roldan-Segura C., Perales-Palacios F.J., Ruiz Granado F. (2018) Enseñando a programar por ordenador en la resolución de problemas de Física de Bachillerato. Revista Eureka sobre Enseñanza y Divulgación de las Ciencias 15 (1), 1301-1317. https://revistas.uca.es/index.php/eureka/article/view/3520

Román V., Capozzo L. (2010). Darwin 2.0. La teoría de la evolución en el siglo XXI. Buenos Aires: Marea Ed.

Ruiz Gutiérrez R., Álvarez-Pérez E., Noguera-Solano R., Esparza-Soria M.S. (2012) Enseñar y aprender Biología evolutiva en el siglo XXI. Bio-grafia: escritos sobre la biología y la enseñanza 5 (9), 80-88. 
Scally C., Alonso M., Garófalo S.J. (2015) Intercambio de roles: Una propuesta didáctica con un videojuego para el aprendizaje de las bases moleculares de los cambios evolutivos. Actas IV Jornadas de Enseñanza e Investigación Educativa en el campo de las Ciencias Exactas y Naturales, La Plata, Argentina.

Smetana L.K., Bell R.L. (2012) Computer Simulations to Support Science Instruction and Learning: A critical review of the literature. International Journal of Science Education 34 (9), 1337-1370.

Torres-Zúñíga V. (2011) Aplicación de weblogs para incrementar el aprendizaje sobre termodinámica a nivel preuniversitario. Revista Eureka sobre Enseñanza y Divulgación de las Ciencias 8 (1), 71-83.https:// revistas.uca.es/index.php/eureka/article/view/2694

Valverde-Crespo D., De Pro A., González-Sánchez J. (2018) La competencia informacionaldigital en la enseñanza y aprendizaje de las ciencias en la educación secundaria obligatoria actual: una revisión teórica. Revista Eureka sobre Enseñanza y Divulgación de las Ciencias 15 (2), 2015. https:// revistas.uca.es/index.php/eureka/article/view/4193

Zangara A., Sanz C. (2012) Aproximaciones al concepto de interactividad educativa. I Jornadas de Difusión y Capacitación de Aplicaciones y Usabilidad de la Televisión Digital Interactiva. La Plata: Argentina. 